\title{
Linearised model for PV panel power output variation with changes in ambient conditions
}

\author{
PALLAVI BHARADWAJ*i] and VINOD JOHN \\ Department of Electrical Engineering, Indian Institute of Science, Bangalore 560012, India \\ e-mail: bharadwaj@ee.iisc.ernet.in
}

MS received 9 March 2017; accepted 29 May 2017; published online 26 October 2017

\begin{abstract}
In closed loop control of PV systems it is important to model the small signal variation of PV panel array output with ambient conditions, namely irradiation and temperature. Changes in these conditions act as a disturbance to the system, but this disturbance needs to be reflected in terms of the quantity being controlled, which can be the PV panel current or the real power. In this work a linearised model is derived to relate the change in system input, namely: irradiance and temperature, with its output, namely: array current and power. The proposed model is experimentally verified with tests run on PV panels, when they are subjected to varying irradiation and temperature conditions in the laboratory. The experimental results confirm the accuracy of the linearised PV panel model.
\end{abstract}

Keywords. Photo-voltaic module; linearised model; irradiation dependence; temperature variation; experimental validation.

\section{Introduction}

A PV array can be modelled using the single-diode model of a solar cell as shown in figure 1 , with appropriate scaling according to the number of solar cells in series and parallel [1]. This model has five modelling parameters, namely: light-induced current $I_{L}$, diode dark saturation current $I_{s}$, diode quality factor $m$, series resistance $R_{s}$ and shunt resistance $R_{s h}$. These modelling parameters can be estimated using either datasheet-based approach [3-7] or measurement-based methods [8-13]. Once the parameters are established, the output of the PV system can be predicted for any day and time conditions. However, this output is in terms of the complete current-voltage characteristics. The point of operation on this new characteristic depends on the load line. Under practical conditions of operation, when the dc power produced by the PV array is fed to the load through a converter, usually a closed loop control is employed. A sudden change in the ambient conditions can be modelled as a disturbance input to the system. To analyse the stability of the controller, the fundamental question is to model this disturbance input in terms of the quantity under control, which for the present analysis is the power output of the PV array. A linearised small signal input output model of the PV array is useful as it can then be incorporated into the model of the balance of the PV system.

*For correspondence

\section{Theory}

PV panel's terminal current versus voltage equation can be written as follows:

$$
i=I_{L}-I_{s}\left(\exp \left(\frac{v+i R_{s}}{m n_{s} V_{t}}\right)-1\right)-\frac{v+i R_{s}}{R_{s h}} .
$$

Before the disturbance from ambience, the system is assumed to operate at a fixed load line representing an equivalent resistance. This equivalent resistance represents the load seen at the PV panel terminals. It is dependent on the actual power drawn by the system and the interfacing converter between the PV panels and the load. Thus it is a function of the converter duty ratio and load characteristics. Due to the disturbance, output characteristics of the PV system shift to a new curve. This is shown in figure 2 . However, the load line remains at its initial value unless there is a change in the load or operating duty ratio of the converter.

To study the variation of system output with ambient conditions, a linearised model can be established based on the parameters of PV panel that change with ambient conditions. These parameters are light-induced current $I_{L}$ and diode dark saturation current $I_{s}$. The dependence of these variables on ambient conditions is modelled in literature [14] as follows:

$$
I_{L}=\frac{G}{G_{r e f}}\left(I_{L_{r e f}}+K_{I_{s c}}\left(T-T_{r e f}\right)\right),
$$




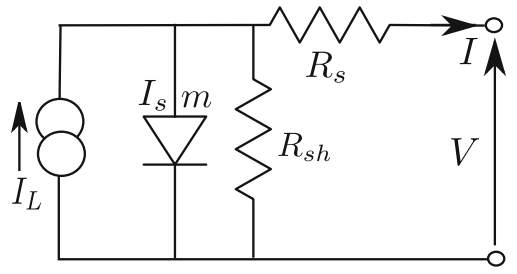

Figure 1. Single-diode model of a solar cell [2].
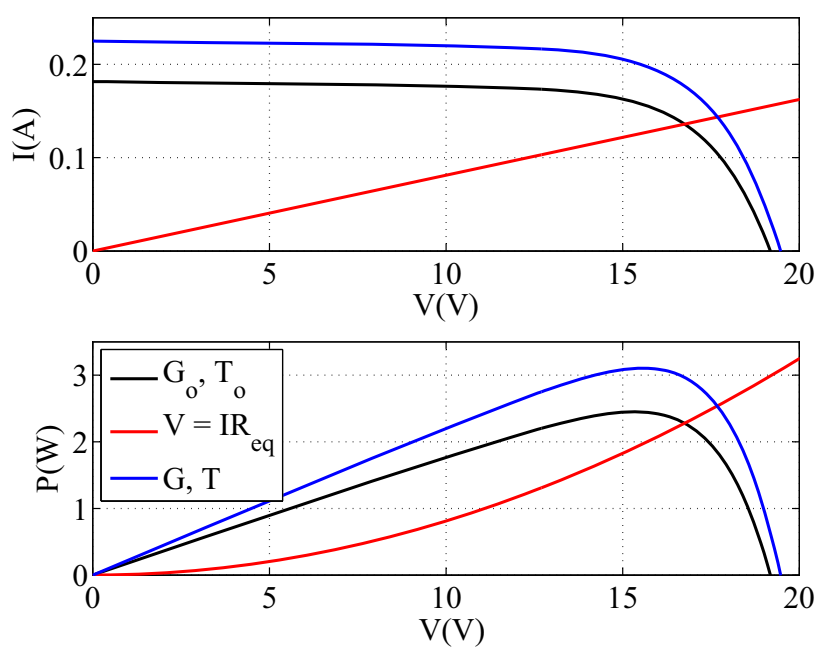

Figure 2. Simulated characteristics of $10 \mathrm{~W}$ PV panel when irradiated with a halogen lamp, for two different irradiation levels $G_{o}, T_{o}$ represent initial ambient conditions and $G, T$ represent changed ambient conditions. Load line is represented by the equation $V=I R_{e q}$, where $R_{e q}$ represents equivalent resistance, which is a function of converter duty cycle ratio.

$$
I_{s}=I_{s_{r e f}}\left(\frac{T}{T_{r e f}}\right)^{3} \exp \left(\frac{q E_{g}}{m k}\left(\frac{1}{T_{r e f}}-\frac{1}{T}\right)\right) .
$$

Hence, the PV panel current can be written as a function of light, temperature and voltage:

$$
i=f(G, T, v) \text {. }
$$

Often a power converter is used to interface the PV panel to a load. As described earlier, for a constant load and converter duty ratio, the equivalent resistance, and therefore the slope of the load line, is constant. Assuming the interfacing $\mathrm{dc}-\mathrm{dc}$ converter to be the boost converter, the relation between voltage and current can be written as follows:

$$
\frac{v}{i}=\text { constant }=R_{e q}=R_{o}(1-d)^{2} .
$$

This is valid for the continuous conduction mode (CCM) of a boost converter [15]. Similar equivalent resistances can be derived for other types of $\mathrm{dc}-\mathrm{dc}$ converters also. Thus, output power of PV panel can be computed as follows:

$$
p=v i=R_{e q} i^{2}
$$

Now, variation in this output power with changing ambient conditions can be evaluated as follows:

$$
\begin{aligned}
& \frac{\partial p}{\partial G}=R_{e q} \times 2 i \frac{\partial i}{\partial G} \\
& \frac{\partial p}{\partial T}=R_{e q} \times 2 i \frac{\partial i}{\partial T} .
\end{aligned}
$$

Total change in power due to changes in ambient conditions can be evaluated as follows:

$$
\left.\Delta P_{G, T}\right|_{o}=R_{e q} \times 2 I_{o}\left(\left.\Delta G_{o} \frac{\partial i}{\partial G}\right|_{o}+\left.\Delta T_{o} \frac{\partial i}{\partial T}\right|_{o}\right) .
$$

It must be noted that irradiation and temperature are interdependent ambient conditions and influence each other; however, to study their explicit effect on the system this linearised small-signal model is proposed here, which allows the application of superposition, and individual effects of these ambient conditions can therefore be studied. Differentiating (1) with respect to $G$ and $T$, one obtains the sensitivity of the PV panel output current with respect to irradiation and temperature:

$$
\begin{gathered}
\left.\frac{\partial i}{\partial G}\right|_{o}=\frac{\left.\frac{\partial I_{L}}{\partial G}\right|_{o}-\left.\frac{\partial I_{s}}{\partial G}\right|_{o}\left(\exp \left(\frac{V_{o}+I_{o} R_{s}}{m n_{S} V_{T_{o}}}\right)-1\right)}{1+\frac{R_{s}+R_{e q}}{R_{s h}}+I_{S_{o}} \frac{R_{s}+R_{e q}}{m n_{s} V_{T_{o}}} \exp \left(\frac{V_{o}+I_{o} R_{s}}{m n_{S} V_{T_{o}}}\right)}, \\
\left.\frac{\partial i}{\partial T}\right|_{o}=\frac{\left.\frac{\partial I_{L}}{\partial T}\right|_{o}-\left.\frac{\partial I_{s}}{\partial T}\right|_{o}\left(\exp \left(\frac{V_{o}+I_{o} R_{s}}{m n_{S} V_{T_{o}}}\right)-1\right)}{1+\frac{R_{s}+R_{e q}}{R_{s h}}+I_{S_{o}} \frac{R_{s}+R_{e q}}{m n_{s} V_{T_{o}}} \exp \left(\frac{V_{o}+I_{o} R_{s}}{m n_{S} V_{T_{o}}}\right)} .
\end{gathered}
$$

However, Eqs. (10) and (11) involve the sensitivities of $I_{L}$ and $I_{s}$ to the ambient conditions $G$ and $T$. They can be obtained using the relationships (2) and (3). Differentiating Eq. (2) with respect to $G$ and $T$, one obtains the sensitivity of the light-induced current with respect to irradiation and temperature:

$$
\begin{gathered}
\left.\frac{\partial I_{L}}{\partial G}\right|_{o}=\frac{I_{L_{r e f}}+K_{I_{s c}}\left(T_{o}-T_{r e f}\right)}{G_{r e f}}, \\
\left.\frac{\partial I_{L}}{\partial T}\right|_{o}=\frac{G_{o} K_{I_{s c}}}{G_{r e f}} .
\end{gathered}
$$

Differentiating Eq. (3) with respect to $G$ and $T$, one obtains the sensitivity of the diode dark saturation current with respect to irradiation and temperature:

$$
\begin{aligned}
\left.\frac{\partial I_{s}}{\partial T}\right|_{o}= & I_{s_{r e f}}\left[\frac{3 T_{o}^{2}}{T^{3}} \exp \left(\frac{q E_{g}}{m k}\left(\frac{1}{T_{r e f}}-\frac{1}{T_{o}}\right)\right)\right. \\
& \left.+\frac{T_{o}^{3}}{T_{r e f}^{3}} \exp \left(\frac{q E_{g}}{m k}\left(\frac{1}{T_{r e f}}-\frac{1}{T_{o}}\right)\right) \frac{q E_{g}}{m k T_{o}^{2}}\right],
\end{aligned}
$$




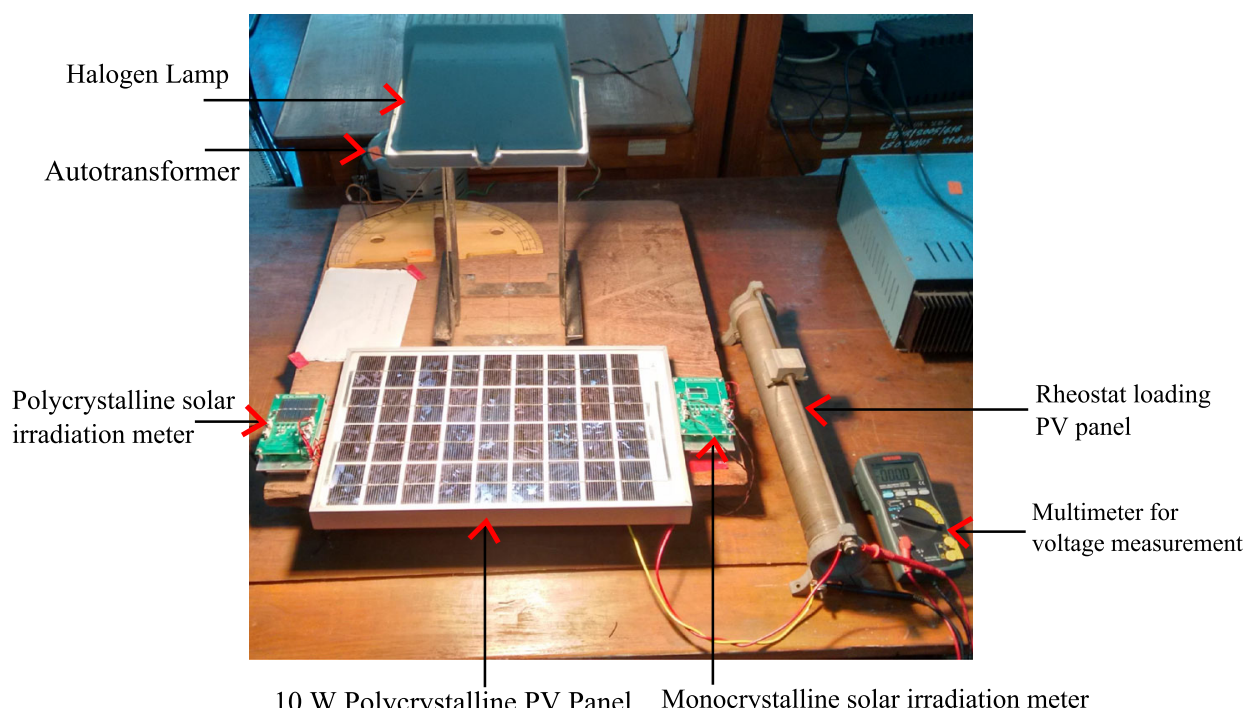

Figure 3. Hardware set-up used for experimental validation of ambient-condition-based linearised model of PV panels.

$$
\left.\frac{\partial I_{s}}{\partial G}\right|_{o}=0
$$

Substituting these expressions in Eqs. (10) and (11), the variation of $\mathrm{PV}$ panel terminal current as a function of temperature and irradiation variation are determined:

$$
\begin{aligned}
&\left.\frac{\partial i}{\partial T}\right|_{o}= \frac{G_{o} K_{I_{s c}}}{G_{r e f}}-I_{s_{r e f}}\left[\frac{3 T_{o}^{2}}{T^{3}} \exp \left(\frac{q E_{g}}{m k}\left(\frac{1}{T_{r e f}}-\frac{1}{T_{o}}\right)\right)\right. \\
&+\left.\frac{T_{o}^{3}}{T_{r e f}^{3}} \exp \left(\frac{q E_{g}}{m k}\left(\frac{1}{T_{r e f}}-\frac{1}{T_{o}}\right)\right) \frac{q E_{g}}{m k T_{o}^{2}}\right] \\
& \times \frac{\left(\exp \left(\frac{V_{o}+I_{o} R_{s}}{m n_{s} V_{T_{o}}}\right)-1\right)}{1+\frac{R_{s}+R_{e q}}{R_{s h}}+I_{S_{o}} \frac{R_{s}+R_{e q}}{m n_{s} V_{T_{o}}} \exp \left(\frac{V_{o}+I_{o} R_{s}}{m n_{s} V_{T_{o}}}\right)}, \\
&\left.\frac{\partial i}{\partial G}\right|_{o}=\frac{\frac{I_{L_{r e f}}+K_{I_{s c}}\left(T_{o}-T_{r e f}\right)}{G_{r e f}}}{1+\frac{R_{s}+R_{e q}}{R_{s h}}+I_{S_{o}} \frac{R_{s}+R_{e q}}{m n_{s} V_{T_{o}}} \exp \left(\frac{V_{o}+I_{o} R_{s}}{m n_{S} V_{T_{o}}}\right)} .
\end{aligned}
$$

Now, $\Delta P_{G, T}$ at a given operating point corresponding to the given initial state of $G_{o}, T_{o}, V_{o}, I_{o}$ and $P_{o}$, can be calculated using Eq. (9). This provides the small-signal linearised model of the power output from the panel for small changes in ambient conditions of irradiation and temperature.

Using this model in tandem with power converter model, wherein a relation between converter duty ratio and PV terminal current is established [16], the complete PV system can be modelled and its performance can be analysed.

\section{Experimental validation}

Experimental validation of the linearised model derived earlier was performed using the experimental set-up shown in figure 3. An autotransformer is used to increase the light
Table 1. Constants used in the analysis.

\begin{tabular}{lc}
\hline Irradiation at STC: $G_{r e f}$ & $1000 \mathrm{~W} / \mathrm{m}^{2}$ \\
Temperature at STC: $T_{r e f}$ & $25^{\circ} \mathrm{C}$ \\
Electron charge: $q$ & $1.6 \times 10^{-19} \mathrm{C}$ \\
Boltzmann's constant: $k$ & $1.38 \times 10^{-23} \mathrm{~J} / \mathrm{K}$ \\
Silicon band gap: $E_{g}$ & $1.12 \mathrm{eV}$ \\
\hline
\end{tabular}

Table 2. Parameters obtained for $10-\mathrm{W}$ panel.

\begin{tabular}{lc}
\hline Light-induced current at STC: $I_{L_{r e f}}$ & $0.650 \mathrm{~A}$ \\
Dark saturation current at STC: $I_{S_{r e f}}$ & $0.228 \mu \mathrm{A}$ \\
Light-induced current at equilibrium: $I_{L_{o}}$ & $0.171 \mathrm{~A}$ \\
Dark saturation current at equilibrium: $I_{S_{o}}$ & $0.463 \mu \mathrm{A}$ \\
Series resistance: $R_{S}$ & $1.48 \Omega$ \\
Shunt resistance: $R_{s h}$ & $2199.8 \Omega$ \\
Diode quality factor: $m$ & 1.5641 \\
Thermal voltage: $V_{T_{o}}$ & $k T_{o} / q$ \\
\hline
\end{tabular}

intensity of the halogen lamp. Irradiation and temperature measurements are made with the help of the solar-cellbased irradiation meter [17]. Corresponding to the increased light and temperature, new output power is noted and compared to the previous equilibrium value. Constants that are used in the analysis are listed in table 1 . The $10-\mathrm{W}$ PV panel parameters, as derived using [1], are listed in table 2. Equations (2) and (3) are used to calculate the parameters corresponding to the equilibrium condition. In this experiment, the equivalent resistance, which determines the slope of load line, was kept fixed to $R_{e q}=123.2 \Omega$, as its slope is close to the MPP slope.

On comparison, it has been observed that the experimental results match well with the theoretical results, as derived from the developed linearised model. The error will further reduce when variation of thermal voltage $V_{T}$ with temperature is included in the analysis. The results are 
Table 3. Comparison of experimental results with theoretical results.

\begin{tabular}{ccccccccc}
\hline$T_{o}$ & $\begin{array}{c}G_{o} \\
{ }^{\circ} \mathrm{C}\end{array}$ & $\times 0.65 \mathrm{~W} / \mathrm{m}^{2}$ & $\times 0.65 \mathrm{~W} / \mathrm{m}^{2}$ & $\begin{array}{c}\Delta T_{o} \\
{ }^{\circ} \mathrm{C}\end{array}$ & $\begin{array}{c}I_{o} \\
\mathrm{~A}\end{array}$ & $\begin{array}{c}V_{o} \\
\mathrm{~V}\end{array}$ & $\begin{array}{c}P_{o} \\
\mathrm{~W}\end{array}$ & $\begin{array}{c}\Delta P_{o}^{e x} \\
\mathrm{~W}\end{array}$ \\
\hline 30 & 428.8 & 102.2 & 1 & 0.137 & 16.82 & 2.296 & 0.295 \\
31 & 443.3 & 095.0 & 1 & 0.136 & 16.74 & 2.277 & 0.275 \\
32 & 435.3 & 109.8 & 1 & 0.136 & 16.74 & 2.277 & 0.257 & 0.274 \\
33 & 440.6 & 106.2 & 1 & 0.136 & 16.80 & 2.292 & 0.257 \\
34 & 435.7 & 101.5 & 1 & 0.136 & 16.70 & 2.271 & 0.278 & 0.271 \\
\hline
\end{tabular}

listed in table 3 . On an average, percentage change in the light conditions was $\frac{\left\langle\Delta G_{o}\right\rangle}{\left\langle G_{o}\right\rangle}=23.6 \%$, which gave an average percentage change in the power output of the $10 \mathrm{~W}$ PV panel of $\frac{\left\langle\Delta P_{o}^{t h}\right\rangle}{\left\langle P_{o}\right\rangle}=12.4 \%$. A change of temperature $\Delta T_{o}$ of $1^{\circ} \mathrm{C}$ was also considered in the experimental studies. The change in temperature of the panel corresponds to the change in temperature that occurs when the halogen lamp intensity is adjusted. An LM35-based temperature sensor is used to measure temperature, which has $98 \%$ accuracy in the given temperature range [17]. Root mean square error (RMSE) between the experimental and theoretical results comes out to be

$$
R M S E=\sqrt{\frac{\sum_{i=1}^{5}\left(\Delta P_{o, i}^{\exp }-\Delta P_{o, i}^{t h}\right)^{2}}{5}}=0.024 \mathrm{~W} .
$$

Coefficient of variance $(\mathrm{CV})$ for RMSE is seen to be

$$
C V(R M S E)=\frac{R M S E}{<\Delta P_{o, i}^{t h}>}=8.59 \%
$$

Normalised error can be computed as

$$
\frac{R M S E}{\left\langle P_{o}\right\rangle}=1.06 \% \text {. }
$$

Thus the total normalised error is within $1.1 \%$.

\section{Conclusion}

Modelling of the input disturbance is explicitly studied using a linearised model, wherein the effect of the changes in the input ambient conditions is quantified in terms of the change in the measurable power output of PV system. The effect of irradiation and temperature on PV system parameters and further on terminal current and power is modelled using a linearised small-signal model based on partial differentiation of PV characteristic equation. The model predicts $12.4 \%$ change in the PV power corresponding to $23.6 \%$ change in the light conditions. Experimental results validate the predicted model, with a normalised error of less than $1.1 \%$. Overall, based on this analysis, it is possible to evaluate the small-signal linearised model of a closed loop PV system considering disturbance in ambient conditions.

\section{Acknowledgements}

This work was supported by CPRI, Ministry of Power, Government of India, under the project "Power conversion, control and protection technologies for microgrid".

\section{References}

[1] Chatterjee A, Keyhani A and Kapoor D 2011 Identification of photovoltaic source models. IEEE Trans. Energy Convers. 26(3): 883-889

[2] Bharadwaj P, Chaudhury K N and John V 2016 Sequential optimization for PV panel parameter estimation. IEEE J. Photovolt. 6(5): 1261-1268

[3] Babu B C and Gurjar S 2014 A novel simplified two-diode model of photovoltaic (PV) module. IEEE J. Photovolt. 4(4): $1156-1161$

[4] Xiao W, Edwin F F, Spagnuolo G and Jatskevich J 2013 Efficient approaches for modeling and simulating photovoltaic power systems. IEEE J. Photovolt. 3(1): 500-508

[5] Breitenstein O 2014 An alternative one-diode model for illuminated solar cells. IEEE J. Photovolt. 4(3): 899-905

[6] Xiao W, Dunford W and Capel A 2004 A novel modeling method for photovoltaic cells. In: Proceedings of the Power Electronics Specialists Conference, vol. 3, June, pp. $1950-1956$

[7] Mahmoud Y, Xiao W and Zeineldin H 2012 A simple approach to modeling and simulation of photovoltaic modules. IEEE Trans. Sustain. Energy 3(1): 185-186

[8] Caracciolo F, Dallago E, Finarelli D G, Liberale A and Merhej P 2012 Single-variable optimization method for evaluating solar cell and solar module parameters. IEEE $J$. Photovolt. 2(2): 173-180

[9] Cristaldi L, Faifer M, Rossi M and Ponci F 2012 A simple photovoltaic panel model: characterization procedure and evaluation of the role of environmental measurements. IEEE Trans. Instrum. Meas. 61(10): 2632-2641

[10] Zhang L and FeiBai Y 2005 Genetic algorithm-trained radial basis function neural networks for modelling photovoltaic panels. Eng. Appl. Artif. Intell. 18(7): 833-844

[11] Adamo F, Attivissimo F, DiNisio A, Lanzolla A and Spadavecchia M 2009 Parameters estimation for a model of 
photovoltaic panels. In: Proceedings of the XIX IMEKO World Congress on Fundamental Applications of Metrology, September, pp. 6-11

[12] Attivissimo F, DiNisio A, Savino M and Spadavecchia M 2012 Uncertainty analysis in photovoltaic cell parameter estimation. IEEE Trans. Instrum. Meas. 61(5): 1334-1342

[13] Blanes J M, Toledo F J Montero S and Garrigós A 2013 Insite real-time photovoltaic I-V curves and maximum power point estimator. IEEE Trans. Power Electron. 28(3): 1234-1240

[14] Villalva M, Gazoli J and Filho E 2009 Comprehensive approach to modeling and simulation of photovoltaic arrays. IEEE Trans. Power Electron. 24(5): 1198-1208
[15] Erickson R W and Maksimovic D 2009 Fundamentals of power electronics. 2nd edn. Springer: New Delhi

[16] Bharadwaj P and John V 2017 High performance buck-boost converter based PV characterisation set. In: Proceedings of the IEEE Energy Conversion Congress and Exposition, October, accepted for publication

[17] Bharadwaj P and John V 2016 Design, fabrication and evaluation of solar cell based irradiation meter for PV applications. J. Instrum. Soc. India 46(2): 78-83 